\title{
Impressions of presidents: Effects of information, time, and discrepancy
}

\author{
ANDREW J. SOSTEK \\ Adult Psychiatry Branch, National Institute of Mental Health, Washington, D.C. 20032
}

and

\author{
ANITA MILLER SOSTEK \\ Georgetown University School of Medicine, Washington, D.C. 20007
}

\begin{abstract}
Sequence types and serial positions affect impression formation based on adjectives or descriptive paragraphs. The present study involved ratings of U.S. presidents after presentation of favorable and unfavorable paragraphs of information. Instructional sets (equal weight or discounting), time spans (long or short), paragraph sets (balanced or discrepant for positive and negative information), and sequence types were manipulated. The results indicate that every sequence type was discriminated and instructions had no effect on impressions. Ratings were higher under the long time span for the discrepant, but not under the balanced, paragraph set. The data were compared with previous studies of impression formation based on the simpler adjective stimuli.
\end{abstract}

Personality impression formation has typically been investigated by varying affective consistency, dispositional levels, and set sizes with adjective materials (Anderson, 1968; Anderson \& Jacobson, 1965; Rywick, 1971). Recently, information integration theory has been applied to the formation of social and political attitudes by studying impressions of past presidents based on descriptive paragraphs (Anderson, 1973; Anderson \& Farkas, 1973; Sawyers \& Anderson, 1971). The results of these studies generally parallel personality judgments based on adjectives. Following the original paradigm, investigators counterbalance specific presidents, paragraph presentation orders, and favorable-unfavorable sequence types. No effects are found for presidents or presentation orders, but sequence types are generally discriminated.

Although information integration theory assumes stimulus independence, inconsistencies among stimuli can interact and alter stimulus weights (Anderson, 1974). When faced with such inconsistency, one resolution strategy is to discount or reduce the weight of the discrepant information (Levin \& Schmidt, 1970). A number of studies on adjective traits have attempted to influence this process by manipulating instructional set (Anderson \& Jacobson, 1965; Gollob \& Lugg, 1973; Kaplan, 1973). Efforts to influence impressions by varying temporal intervals between adjectives have been largely unsuccessful (Hendrick, Constantini, McGarry \& McBride, 1973; Rywick \& Schaye, 1974).

We acknowledge the thoughtful comments of Norman Anderson. Address correspondence to Andrew Sostek, Adult Psychiatry Branch, Special Mental Health Research, NIMH, St. Elizabeth's Hospital, William Alanson White Building, Washington, D.C. 20032.
Our study was designed to investigate the effects of instructional sets on impressions of presidents. The information was presented under equal weighting and discounting instructions, in long and short time spans, and within balanced and discrepant paragraph sets. It was hypothesized that ratings would differ among sequence types. Because of the complex nature of the stimuli, variation in time spans was expected to influence information integration. We further hypothesized that instructions would interact with paragraph sets, with discounting effective for the discrepant set, which contains inconsistent weights, but not for the balanced set, which contains equal amounts of favorable and unfavorable information.

\section{METHOD}

Subjects

The subjects were 64 female college students taking introductory psychology at the State University of New York at Buffalo.

\section{Procedure}

Eight paragraphs (four highly favorable and four highly unfavorable) were selected from Anderson, Sawyers, and Farkas (1972) for each of eight presidents: Thomas Jefferson, James Monroe, Theodore Roosevelt, William Howard Taft, Andrew Jackson, Grover Cleveland, Woodrow Wilson, and Harry Truman. Each subject was asked to rate a set of four paragraphs for each president on an 8-point scale ranging from highly unfavorable to highly favorable, counterbalanced for order (1 to 8 or 8 to 1 ). For the purpose of data analysis, the ratings were adjusted so that 8 always indicated the most favorable impression. The total possible ratings for each president ranged from 4 to 32 points.

Prior to beginning, the subjects read a brief history summary and five familiarization paragraphs, which provided favorable and unfavorable anchor points. They were told to judge each president on the general quality of his statesmanship and how 
well he did his job in the context of his own times and their problems. The ratings were continuous, with the response to each paragraph based on the cumulation of information to that point. The subjects were given $40 \mathrm{sec}$ to read each paragraph and $20 \mathrm{sec}$ between presidents.

The 64 subjects were randomly assigned to eight groups, with 8 subjects at each level of a 2 by 2 by 2 factorial design. The three factors were (1) instructional set (equal weighting or discounting), (2) time spans (short or long), and (3) balanced or discrepant paragraph sets. The equal-weighting condition instructed the subjects to consider the paragraphs equally because they were all written by reputable historians. Under the discounting instructions, the subjects were told to discount inconsistent information about a particular president because some historians may be biased and have an ax to grind. The short and long time spans were 7 and $22 \mathrm{sec}$ to consider the material without looking at the paragraphs.

The balanced paragraph set included the sequences with four high $(4 \mathrm{H})$, four low $(4 \mathrm{~L})$, and the six possible combinations of $2 \mathrm{H}$ and $2 \mathrm{~L}$ stimuli. The discrepant paragraph set included all eight sequences with $3 \mathrm{H}$ and $1 \mathrm{~L}$ or $3 \mathrm{~L}$ and $1 \mathrm{H}$ stimuli. As indicated in Table 1, there was a total of 16 sequence types. Within each group, the paragraphs were ordered according to an 8 by 8 Greco-Latin square including eight levels of presidents, presentation orders, sequence types, and subjects.

\section{RESULTS}

Two sets of analyses were performed on the data. The first collapsed time spans and instructions and analyzed the Greco-Latin squares for presidents, presentation orders, and sequence types within the balanced and discrepant paragraph sets. Because presidents and presentation orders did not differ, the second set of analyses collapsed them and compared instructional conditions, time spans, paragraph sets, and sequence types. Table 1 presents the means and standard deviations for the ratings based on each possible stimulus sequence.

The overall mean rating of the presidents was 18.96 points. There were no differences between the instructional sets. Time spans interacted with paragraph sets $[F(1,63)=4.97, p<.05]$. Although time spans did not influence impressions for the balanced set, the discrepant paragraph set yielded more favorable ratings with $22 \mathrm{sec}$ to form the impression $[\mathrm{F}(1,63)=4.05$, $\mathrm{p}<.05$ ] (see Table 2). This effect was largely attributable to the $3 \mathrm{~L}$ and $1 \mathrm{H}$ sequence types.

Overall, sequence types influenced ratings as a main

Table 1

Ratings for Each Sequence

\begin{tabular}{ccccccc}
\hline \multicolumn{3}{c}{ Balanced Set } & & \multicolumn{3}{c}{ Discrepant Set } \\
\cline { 1 - 2 } \cline { 5 - 6 } Sequence & Mean & SD & & Sequence & Mean & SD \\
\hline HHHH & 29.38 & 3.23 & LHHH & 21.66 & 4.46 \\
LHLH & 16.82 & 5.13 & HLHH & 23.56 & 4.81 \\
HLLH & 19.09 & 4.28 & HHLH & 25.06 & 4.02 \\
LLHH & 15.88 & 5.87 & HHHL & 27.38 & 3.59 \\
HLHL & 21.44 & 3.76 & HLLL & 16.44 & 4.70 \\
HHLL & 22.75 & 5.15 & LHLL & 13.31 & 4.23 \\
LHHL & 16.78 & 4.75 & LLHL & 12.38 & 4.58 \\
LLLL & 8.63 & 4.70 & LLLH & 12.66 & 5.60 \\
\hline
\end{tabular}

Table 2

Interaction Between Paragraph Sets and Time Spans: Ratings of Presidents

\begin{tabular}{ccc}
\hline & \multicolumn{2}{c}{ Time Span } \\
\cline { 2 - 3 } Paragraph Set or & Short & Long \\
\hline Sequence Type & 18.36 & 19.75 \\
Discrepant* & 24.12 & 24.72 \\
3H and 1L & 12.61 & 14.78 \\
3L and 1H* & 18.92 & 18.77 \\
Balanced (2H and 2L) & & \\
\hline
\end{tabular}

${ }^{*} p<.05$.

Table 3

Ratings for Each Sequence Type

\begin{tabular}{lrl}
\hline Sequence Type & Mean & SD \\
\hline 4H & 29.38 & 3.23 \\
3H and 1L & 24.39 & 4.22 \\
2H and 2L & 18.90 & 4.82 \\
1H and 3L & 13.69 & 4.77 \\
4L & 8.63 & 4.70 \\
\hline
\end{tabular}

effect $[F(15,420)=54.29, p<.00001]$. Sequence types had a significant effect both within the balanced set $[F(7,196)=57.39, p<.001]$ and within the discrepant set $[F(7,196)=68.63, p<.00001]$. When the balanced and discrepant paragraph sets were analyzed together, the $4 \mathrm{H}$ sequence was rated more favorably than the four sequences with $3 \mathrm{H}$ and $1 \mathrm{~L}[\mathrm{~F}(1,420)=7.82, \mathrm{p}<.01]$ (see Table 3 ). The six sequences of $2 \mathrm{H}$ and $2 \mathrm{~L}$ stimuli were judged less favorably. than those of $3 \mathrm{H}$ and $1 \mathrm{~L}$ $[F(1,420)=30.09, p<.0001]$ and more favorably than those of $3 \mathrm{~L}$ and $1 \mathrm{H}[\mathrm{F}(1,420)=24.82, \mathrm{p}<.0001]$. Similarly, ratings were lower for the $4 \mathrm{~L}$ sequence than for that of $3 \mathrm{~L}$ and $1 \mathrm{H}[\mathrm{F}(1,420)=8.17, \mathrm{p}<.01]$. The differences between the mean ratings for each pair of adjacent sequence types on Table 3 ranged from 4.99 to 5.49 , indicating almost equal intervals in the psychological scale values of the presidential paragraphs.

\section{DISCUSSION}

The present findings demonstrate significant differences between every possible pair of sequence types, indicating discrimination between sets including zero, one, two, three, and four favorable or unfavorable presidential paragraphs. Contrary to our hypothesis, the instructions to weigh the paragraphs equally or to discount inconsistent information had no influence on the ratings. Their ineffectiveness parallels similar findings in adjective studies that instructed subjects to minimize discrepancies (Gollob \& Lugg, 1973). Instructions have been effective only when subjects are told to eliminate inconsistent information fully (Anderson \& Jacobson, 1965). Anderson (1974) speculates that people are less bothered by inconsistent information than theorists typically maintain (Abelson, Aronson, McGuire, Newcomb, Rosenberg, \& Tannenbaum, 1968).

Although time spans did not influence ratings of presidents for the balanced paragraph set, ratings were more favorable with additional time in the discrepant set. Studying adjectives, Rywick and Schaye (1974) found that a delay following stimulus presentation did not in itself alter impressions. When an 
irrelevant task was added during the delay period, however, a longer time span influenced the weighting of information. In evaluating the more complex paragraph data, subjects minimized the weight of discrepant unfavorable information when they had additional time to consider their impressions. Whether or not this effect is specific to impressions of presidents is open to speculation. One might expect quite the opposite effect in impressions of prisoners, for example, with favorable rather than unfavorable information minimized over longer intervals of time.

\section{REFERENCES}

Abelson, R. P., Aronson, E., McGuire, W. J., Newcomb, T. M., Rosenberg, M. J., \& Tannenbaum, P. H. (Eds.). Theories of cognitive consistency: A sourcebook. Chicago: Rand McNally, 1968.

Anderson, N. H. A simple model for information integration. In R. P. Abelson, E. Aronson, W. J. McGuire, T. M. Newcomb, M. J. Rosenberg, \& P. H. Tannenbaum (Eds.), Theories of cognitive consistency: $A$ sourcebook. Chicago: Rand McNally, 1968.

ANDE RSON, N. H. Information integration theory applied to attitudes about U.S. presidents. Journal of Educational Psychology, $1973,64,1-8$.

Ande rson, N. H. Information integration theory: A brief survey. In D. H. Krantz, R. C. Atkinson, R. D. Luce, \& P. Suppes (Eds.), Contemporary developments in mathematical psychology. San Francisco: Freeman, 1974.

Anderson, N. H., \& Farkas, N. J. New light on order effects in attitude change. Journal of Personality and Social Psychology, 1973, 28, 88-93.
Anderson, N. H., \& Jacobson, A. Effects of stimulus inconsistency and discounting instructions in personality impression formation. Journal of Personality and Social Psychology, 1965, 2, 531-539.

Anderson, N. H., Sawyers, B. K., \& Farkas, A. J. President paragraphs. Behavior Research Methods \& Instrumentation, 1972, 4, 177-192.

Gollub, H. F., \& LugG, A. M. Effects of instruction and stimulus presentation on the occurrence of averaging responses in impression formation. Journal of Experimental Psychology, 1973, 98, 217-219.

Hendrick, C., Constantini, A. F., McGarry, J., \& McBride, K. Attention decrement, temporal variation and the primacy effect in impression formation. Memory \& Cognition, 1973, 1, 193-195.

KAPLAN, M. Stimulus inconsistency and response disposition in forming judgements of other person. Journal of Personality and Social Psychology, 1973, 25, 58-64.

Levin, I. P., \& Schmidt, C. F. Differential influence of information in an impression formation task with binary intermittent responding. Journal of Experimental Psychology, 1970, 84, 374-376.

Rywick, T. Primacy effects in impression formation as a function of type of impression. Psychonomic Science, 1971, 25, 195-196. RYwick, T., \& Schaye, P. Use of long-term memory in impression formation. Psychological Reports, 1974, 34, 939-945.

SawYers, B. K., \& ANDERSon, N. H. Test of integration theory in attitude change. Journal of Personality and Social Psychology, 1971, 18, 230-233.

(Received for publication March 13, 1981.) 